\title{
Decoding an olfactory mechanism of kin recognition and inbreeding avoidance in a primate Marylène Boulet ${ }^{\dagger 1,4}$, Marie JE Charpentier ${ }^{\dagger 1,2}$ and Christine M Drea*1,3
}

\author{
Address: ${ }^{1}$ Department of Evolutionary Anthropology, 108 BioSci BLDG, Box 90383, Duke University, Durham, North Carolina, 27708, USA, \\ ${ }^{2}$ CEFE-CNRS, 1919 Route de Mende, 34293 Montpellier Cedex 5, France, ${ }^{3}$ Department of Biology, 108 BioSci BLDG, Box 90383, Duke University, \\ Durham, North Carolina, 27708, USA and 4 Department of Biology, Bishop's University, 2600 College Street, Sherbrooke, Québec, J1M 1Z7, \\ Canada \\ Email: Marylène Boulet - mboulet@ubishops.ca; Marie JE Charpentier - mariecharp@yahoo.fr; Christine M Drea* - cdrea@duke.edu \\ * Corresponding author †Equal contributors
}

Published: 3 December 2009

BMC Evolutionary Biology 2009, 9:28I doi:10.1|86/147|-2|48-9-28|
Received: 13 February 2009

Accepted: 3 December 2009

This article is available from: http://www.biomedcentral.com//47I-2I 48/9/28।

(C) 2009 Boulet et al; licensee BioMed Central Ltd.

This is an Open Access article distributed under the terms of the Creative Commons Attribution License (http://creativecommons.org/licenses/by/2.0), which permits unrestricted use, distribution, and reproduction in any medium, provided the original work is properly cited.

\begin{abstract}
Background: Like other vertebrates, primates recognize their relatives, primarily to minimize inbreeding, but also to facilitate nepotism. Although associative, social learning is typically credited for discrimination of familiar kin, discrimination of unfamiliar kin remains unexplained. As sexbiased dispersal in long-lived species cannot consistently prevent encounters between unfamiliar kin, inbreeding remains a threat and mechanisms to avoid it beg explanation. Using a molecular approach that combined analyses of biochemical and microsatellite markers in 17 female and 19 male ring-tailed lemurs (Lemur catta), we describe odor-gene covariance to establish the feasibility of olfactory-mediated kin recognition.

Results: Despite derivation from different genital glands, labial and scrotal secretions shared about 170 of their respective 338 and 203 semiochemicals. In addition, these semiochemicals encoded information about genetic relatedness within and between the sexes. Although the sexes showed opposite seasonal patterns in signal complexity, the odor profiles of related individuals (whether same-sex or mixed-sex dyads) converged most strongly in the competitive breeding season. Thus, a strong, mutual olfactory signal of genetic relatedness appeared specifically when such information would be crucial for preventing inbreeding. That weaker signals of genetic relatedness might exist year round could provide a mechanism to explain nepotism between unfamiliar kin.

Conclusion: We suggest that signal convergence between the sexes may reflect strong selective pressures on kin recognition, whereas signal convergence within the sexes may arise as its byproduct or function independently to prevent competition between unfamiliar relatives. The link between an individual's genome and its olfactory signals could be mediated by biosynthetic pathways producing polymorphic semiochemicals or by carrier proteins modifying the individual bouquet of olfactory cues. In conclusion, we unveil a possible olfactory mechanism of kin recognition that has specific relevance to understanding inbreeding avoidance and nepotistic behavior observed in free-ranging primates, and broader relevance to understanding the mechanisms of vertebrate olfactory communication.
\end{abstract}




\section{Background}

Most vertebrates recognize their close relatives (kin recognition), either to avoid mating with them or to identify the most appropriate recipients of nepotistic behavior (kin discrimination) [1-3]. Although the benefits of kin recognition may be clear, the mechanisms by which it operates are often less evident. In primates, for instance, researchers typically credit associative, social learning in the discrimination of familiar kin $[2,4]$, but the discrimination of unfamiliar kin (e.g. $[5,6])$ defies explanation via associative learning [7]. As sex-biased dispersal cannot consistently prevent kin encounters, particularly in longlived species, inbreeding between unfamiliar kin remains a real threat and carries potentially disastrous fitness consequences [8-10]; consequently, mechanisms to avoid it beg explanation. Indeed, a deeper understanding of communicatory signals demands integration of 'why' questions about ultimate function with 'how' questions about proximate mechanisms [11]. As olfactory-mediated kin discrimination is gaining appreciation in other taxonomic groups $[3,12,13]$, we propose that primates might also use odor cues to assess kinship or genetic relatedness, particularly to identify unfamiliar kin. As a first step to addressing this question, we merge biochemical and genetic analyses to test if olfactory signals offer a reliable means of kin recognition in a strepsirrhine primate, the ring-tailed lemur (Lemur catta).

Research on kin discrimination is typically focused on documenting its occurrence. For instance, under natural conditions, researchers have coupled field observations with genetic analyses to show non-random spatial associations or preferential treatment between unfamiliar kin $[7,14,15]$ and avoidance of unfamiliar relatives as mates [16-19]. In the laboratory, researchers have relied on behavioral bioassays or cross-fostering experiments to assess an individual's ability to differentiate unfamiliar kin from non-kin [3]. Here, we focus instead on deciphering a putative olfactory mechanism of kin recognition by showing odor-gene covariance, which occurs when the similarity between the olfactory signals of two individuals reflects their genetic similarity at specific or multiple loci [20]. In inbred mouse lines, for example, at least two gene families (e.g., the major histocompatibility complex or MHC and mouse urinary proteins or MUPs) influence the olfactory profiles of an individual's urine [21-23] and underlie conspecific recognition [24]. Only a handful of studies have begun to examine if similar results might obtain in non-model vertebrates that have different signaling systems or if additional genes may be involved in creating individual odor profiles. Indeed, the interaural secretions of bats relate to maternal lineages [25], the anal secretions of beavers encode pedigree relationships [26], and the scrotal secretions of male ring-tailed lemurs reflect individual genetic diversity (i.e., neutral, whole-genome heterozygosity) and genetic relatedness among males
[27]. The latter results have significant implications for olfactory-guided female mate choice and male-male competition, suggesting that odor-gene covariance in this species merits further investigation. Here, we complement our prior findings by examining if the olfactory cues common to female and male genital secretions relate to genome-wide relatedness within and, more importantly, between the sexes. If so, olfactory cues could provide a reliable mechanism of kin recognition to guide nepotistic behavior and inbreeding avoidance.

Ring-tailed lemurs live in multi-male multi-female groups, characterized by a promiscuous breeding system, as well as by female philopatry and male-biased dispersal $[28,29]$. As a long-lived species that also experiences female eviction [30] and repeated male migration [29], they face the risk of consanguineous mating with unfamiliar kin. When it occurs, inbreeding may have dire consequences, including depressed immune function and reduced life expectancy [31]. Olfactory communication is critical to lemur social interaction, as evidenced by their unique set of specialized scent glands or glandular fields, their elaborate scent-marking repertoire, and the intensity of response these scent signals elicit from conspecifics [28,32-34]. Here, we focus on the genital secretions derived from the labial glandular fields and the scrotal glands because, beyond encoding identity, these secretions are the most comparable between the sexes $[34,35]$.

We sampled 17 sexually mature females year round, during the extended nonbreeding season and the relatively limited breeding season, following published protocols [35]. Our comparable male data (on $n=19$ adults) derived from a prior study [27]. We used a sequential approach to determine if genital secretions encode information about relatedness within and between the sexes. For the first analysis involving all female-female (FF) dyads, we related differences in the semiochemical secretions between dyads of females to their pairwise genetic distance. This analysis is particularly relevant to examining olfactory mechanisms guiding nepotistic or competitive behavior between members of the same sex. For the second analysis involving all mixed-sex (MF) dyads, we related differences between the semiochemical secretions and pairwise distances in MM, FF, and MF dyads using a subset of semiochemicals shared by the sexes. For the last analyses of odor-gene covariance, we focused exclusively on MF dyads. These latter analyses are of primary relevance to examining olfactory mechanisms of inbreeding avoidance.

\section{Results \\ Sex differences and similarities in signal composition}

Females expressed a greater number of semiochemicals in their genital secretions than did males (total compounds overall: females $=338$, males $=203$; mean \pm SD com- 
pounds in the breeding season: females $=217.8 \pm 20.0$, males $=135.0 \pm 13.5 ;$ t-test, $\mathrm{t}_{34}=14.7, P<0.001 ;$ mean \pm SD compounds in the nonbreeding season: females = $200.1 \pm 19.3$, males $=154.4 \pm 10.5$; t-test for unequal variance, $\left.\mathrm{t}_{24}=8.7, P<0.001\right)$. This sex difference was typically accounted for by the presence in females of additional low-molecular weight compounds, such as fatty acid alcohols. Despite this sex difference in overall expression and despite their distinct anatomical derivation [34], labial and scrotal secretions shared a total of 170 compounds, defined as those compounds expressed in at least one female and one male (representing 50.3\% and $83.7 \%$ of total female and male compounds, respectively; Figure 1). These shared compounds included fatty acid esters (49\%), unknown hydrocarbons with identified molecular mass (25\%), fatty acids (10\%), compounds related to cholesterol (2\%), long-chained alcohols $(2 \%)$, squalene $(<1 \%)$, farnesol $(<1 \%)$, and $1,6,10$-dodecatriene,7,11-dimethyl-3-methylene $(<1 \%)$.

\section{Seasonal sex differences in semiochemical diversity}

The sexes also differed in their seasonal patterns of semiochemical diversity, as reflected by three indices, including Richness (which refers to the number of observed semiochemicals) and the Simpson and Shannon indices (which both correct for semiochemical abundance, see Methods and [36]). In males, genital scent signals showed a consistent decline in semiochemical diversity, across all indices, from the nonbreeding to the breeding season [27]. By contrast, the semiochemical diversity of female scent secretions either increased during the breeding season (Richness index, paired t-test, $\mathrm{t}_{16}=2.43, P=0.03$ ) or remained stable across seasons (Shannon index: $t_{16}=$ $1.25, P=0.23$; Simpson index: $\left.\mathrm{t}_{16}=0.27, P=0.79\right)$, potentially because those compounds gained during the breeding season contributed only a small proportion (less than $0.5 \%$ ) to the total chromatogram area. Thus, during the breeding season, whereas signal complexity was compromised in most males, females maintained or enhanced their signal complexity.

\section{Within-sex odor-gene covariance}

We found that, complementing the pattern in males [27], the olfactory cues present in female genital secretions encoded information about female relatedness in a seasonally dependent fashion. In particular, the chemical distance between members of FF dyads showed no relationship to their genetic distance during the nonbreeding season (partial Mantel test, $\mathrm{r}=-0.07, P=0.39$; Figure $2 \mathrm{~A}$ and $2 \mathrm{C}$ ), but correlated significantly with their genetic distance during the breeding season (partial Mantel test, $\mathrm{r}=0.22, P=0.02$; Figure $2 \mathrm{~B}$ and $2 \mathrm{D}$ ).

\section{Between-sex odor-gene covariance}

Representative chromatograms of related and unrelated MF pairs during the breeding season illustrate the greater semiochemical similarity between, for example, brothersister and mother-son pairs than between two unrelated individuals born to different colonies (Figure 1). To statistically examine the relationship between chemical and genetic distances between mixed-sex pairs, we first ran a partial Mantel test, as above, but for all possible dyads ( $\mathrm{n}$ $=630 \mathrm{MM}+\mathrm{FF}+\mathrm{MF}$ dyads). Overall, chemical and genetic distances did not correlate during the nonbreeding season (partial Mantel test, $r=0.01, P=0.76$ ), but did correlate during the breeding season (partial Mantel test, $r$ =0.13, $P=0.002$ ), consistent with the patterns found independently for same-sex analyses (males: [27]; females: Figure 2).

Next, we extracted from the 630 dyads those pairs involving males and females only $(n=323 \mathrm{MF}$ dyads, Figure $3 \mathrm{~A}$ and $3 \mathrm{~B}$ ). As we could not use the Mantel test for the MF dyads alone (because the corresponding MF matrix would not have been square), we instead used a permutation test to compare the empirical correlation coefficient (Spearman's r) against a distribution of correlation coefficients generated by resampling events [37]. With this analysis, we detected a significant pattern of odor gene-covariance during both the nonbreeding $(\mathrm{r}=0.12, P=0.018)$ and the breeding ( $\mathrm{r}=0.24, P=0.001)$ seasons. According to these tests, the odor-gene covariance appeared to be expressed in mixed-sex pairs throughout the year, but was stronger during the breeding season. For a more conservative analysis, we categorized the $323 \mathrm{MF}$ dyads into five classes of genetic distances (Figure 3C and 3D, as for FF dyads in Figure $2 \mathrm{C}$ and $2 \mathrm{D}$ and as for MM dyads in [27]), which we compared using permutation tests based on class means [38]. During the nonbreeding season, the mean semiochemical distance between members of MF dyads did not vary across classes of genetic distance (all pairwise Ps > $0.05)$; olfactory cues in the nonbreeding season did not reflect the genetic relationship between males and females (Figure 3C). During the breeding season, however, the mean semiochemical distances between members of $\mathrm{MF}$ dyads were significantly differentiated across nearly all classes (pairwise Ps $<0.001$, except for class 0.3-0.4 vs. class $0.4-0.5, P=1.0)$, increasing systematically with genetic distance (Figure 3D). According to this analysis, and consistent with within-sex patterns (Figure 2, [27]), the olfactory cues encoding relatedness between the sexes were evident only during the breeding season.

\section{Discussion}

By integrating genetics and biochemistry, we provide the first molecular evidence that the scent secretions expressed by the genital glands of male and female lemurs contain olfactory markers of genetic relatedness within and, more importantly, between the sexes. To date, convergence in olfactory profiles between relatives had been reported only for same-sex dyads [26,27]. Moreover, although semiochemicals common to both sexes have 

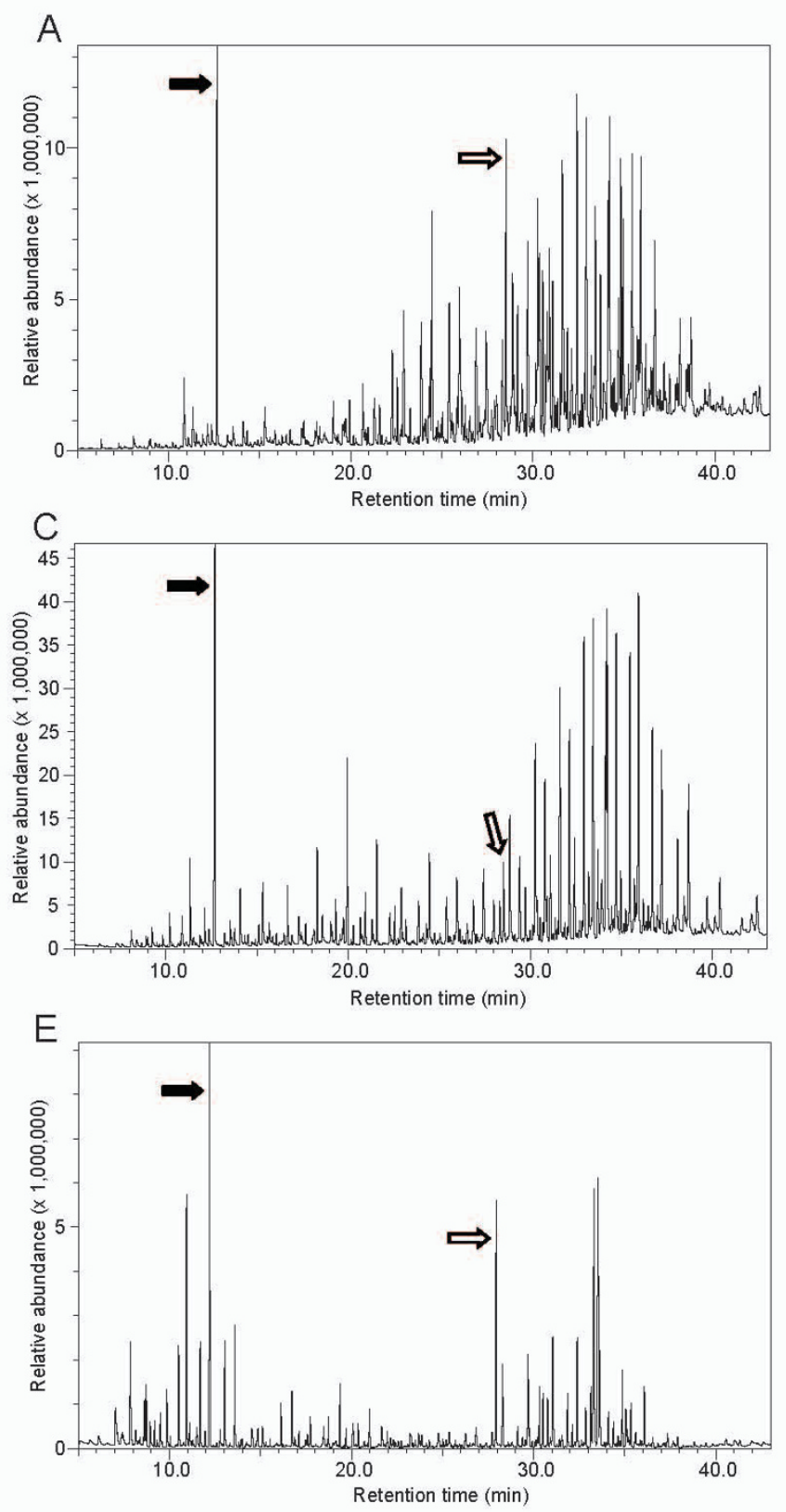
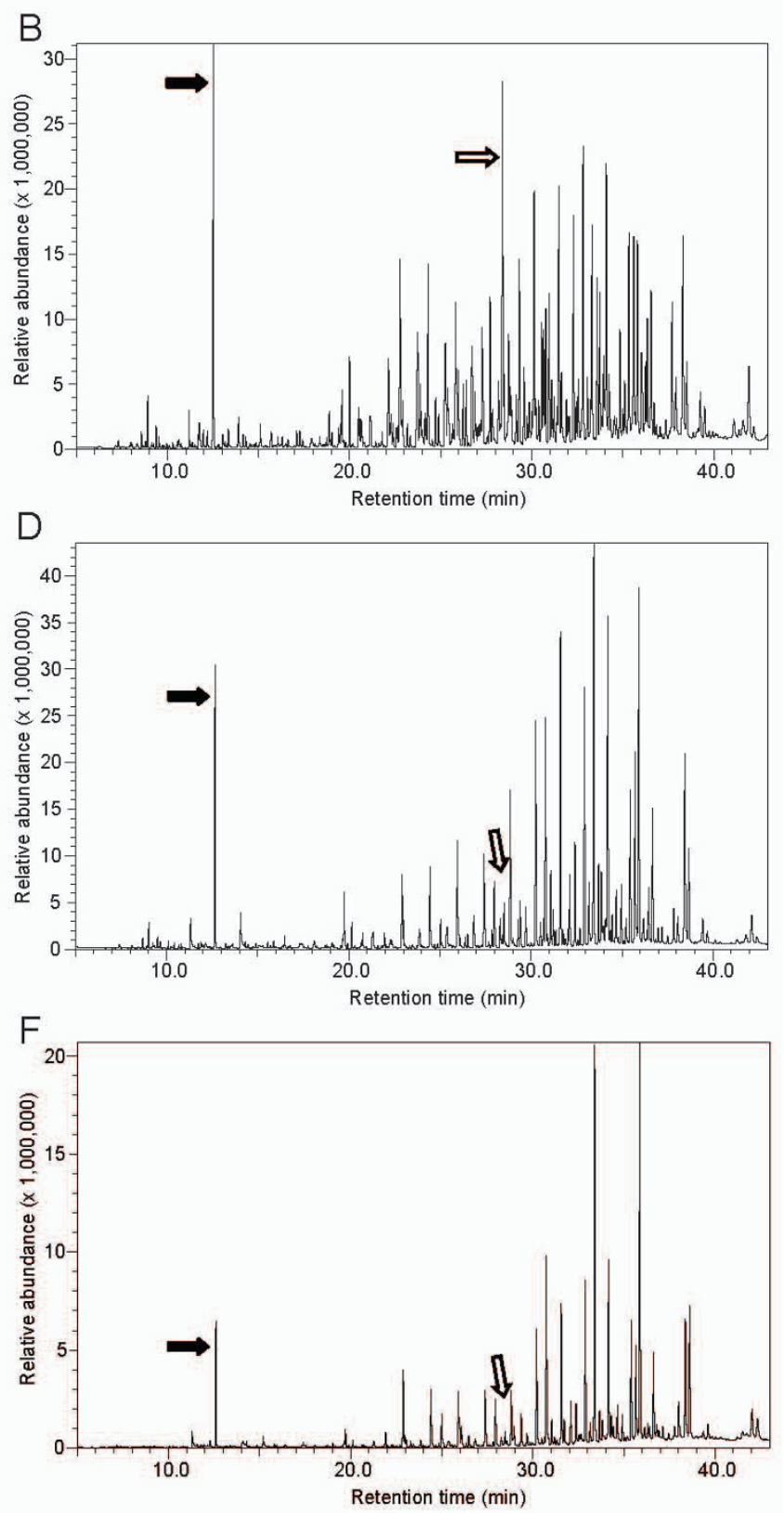

Figure I

Odor profiles of the genital secretions in mixed-sex pairs of related and unrelated lemurs. Chromatograms of labial (first column) and scrotal secretions (second column) from three female-male pairs of lemurs during the breeding season. Top row: maternal half-siblings, representing a sister $(A)$ and her brother $(B)$. For this pair, $D_{I D}=0.28$ and $D_{C}=0.47$. Middle row: mother $(C)$ and son $(D)$. For this pair, $D_{I D}=0.18$ and $D_{C}=0.54$. Bottom row: unrelated female $(E)$ and male $(F)$ born in different colonies. For this pair, $D_{I D}=0.55$ and $D_{C}=1.16$. The filled arrow points to the internal standard, hexachlorobenzene, added to the sample before the GCMS run and the open arrow points to the endogenously produced standard, squalene.

been identified in the secretions derived from the same gland in other species $[12,13]$, we report on signal convergence in the secretions derived from comparable, but anatomically distinct glands or glandular fields [34,39]. Lastly, although the sexes diverged seasonally with respect to their signal complexity, mixed-sex (and same-sex) convergence in the olfactory signals of related individuals appeared most strongly (or only) during the breeding season, suggesting that genital secretions are 'mutual signals' [40] that encode information primarily relevant to 
A
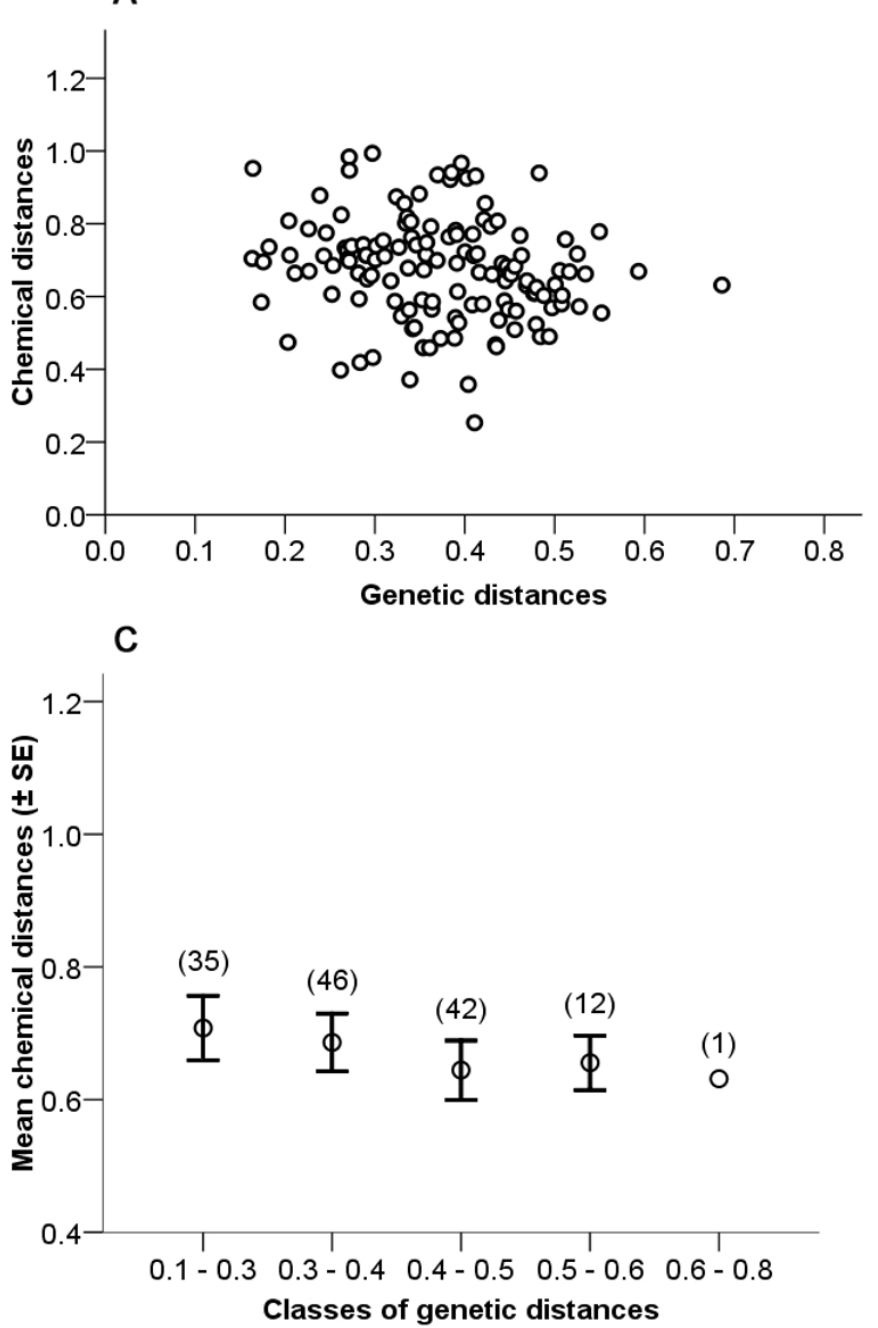

B

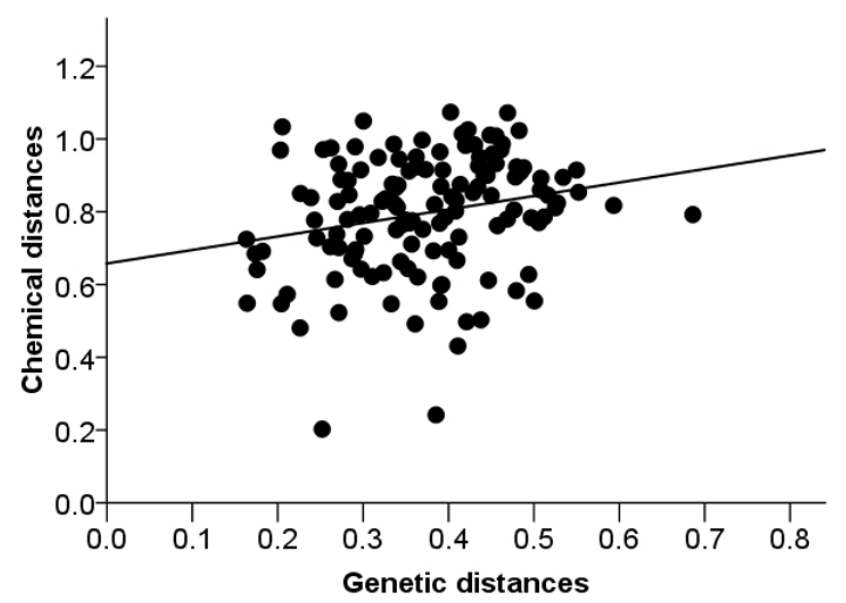

D

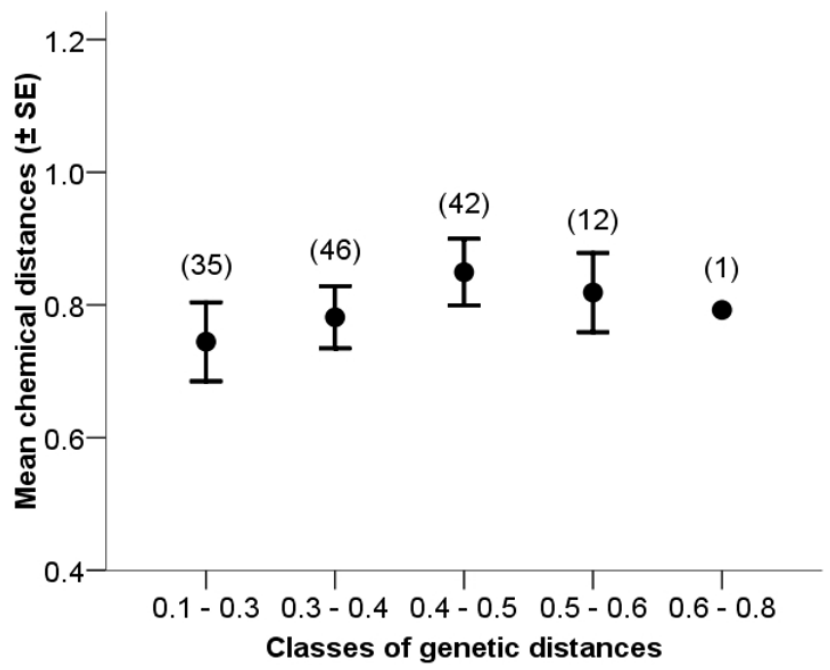

Figure 2

Odor-gene covariance in female-female dyads. Relationships between genetic distances $\left(D_{I D}\right)$ and chemical distances (relative Euclidean, from 338 compounds) in 136 female-female dyads during the nonbreeding (open circles, $A$ and $C$ ) and breeding (filled circles, B and D) seasons. The partial Mantel tests were performed on the data illustrated in A and B. For ease of representation and continuity with [27], in $C$ and D we also show these relationships using mean chemical distances per class of genetic distances.

inbreeding avoidance, with potentially secondary or independent implications for facilitating nepotism year round. The convergence of olfactory signals within and between the sexes likely underlines strong selective pressures on kin recognition.

Whereas for many females the benefit of inbreeding avoidance may be clear (e.g. to avoid the high energy investment of pregnancy and lactation if the offspring produced would be of low quality), the benefit to males may be less apparent, given their seemingly reduced investment in reproduction. What then might be the selection pressures operating on males to explain olfac- tory convergence between the sexes? In some species, the olfactory profiles of certain males converge on those of the females to dupe conspecifics in sex communication [4143]. Such duplicity is unlikely, however, in members of individualized societies. Moreover, it is not supported in ring-tailed lemurs by olfactory evidence, given that sex and individual identity are chemically encoded [35] and detected $[33,34]$ in scent cues throughout the year. An alternate explanation may be found in a broader application of sexual selection theory. Increasing evidence of female-female competition and male mate choice suggests that various species may not conform to a dichotomized pattern of 'expensive eggs' and 'cheap sperm' [44]. 

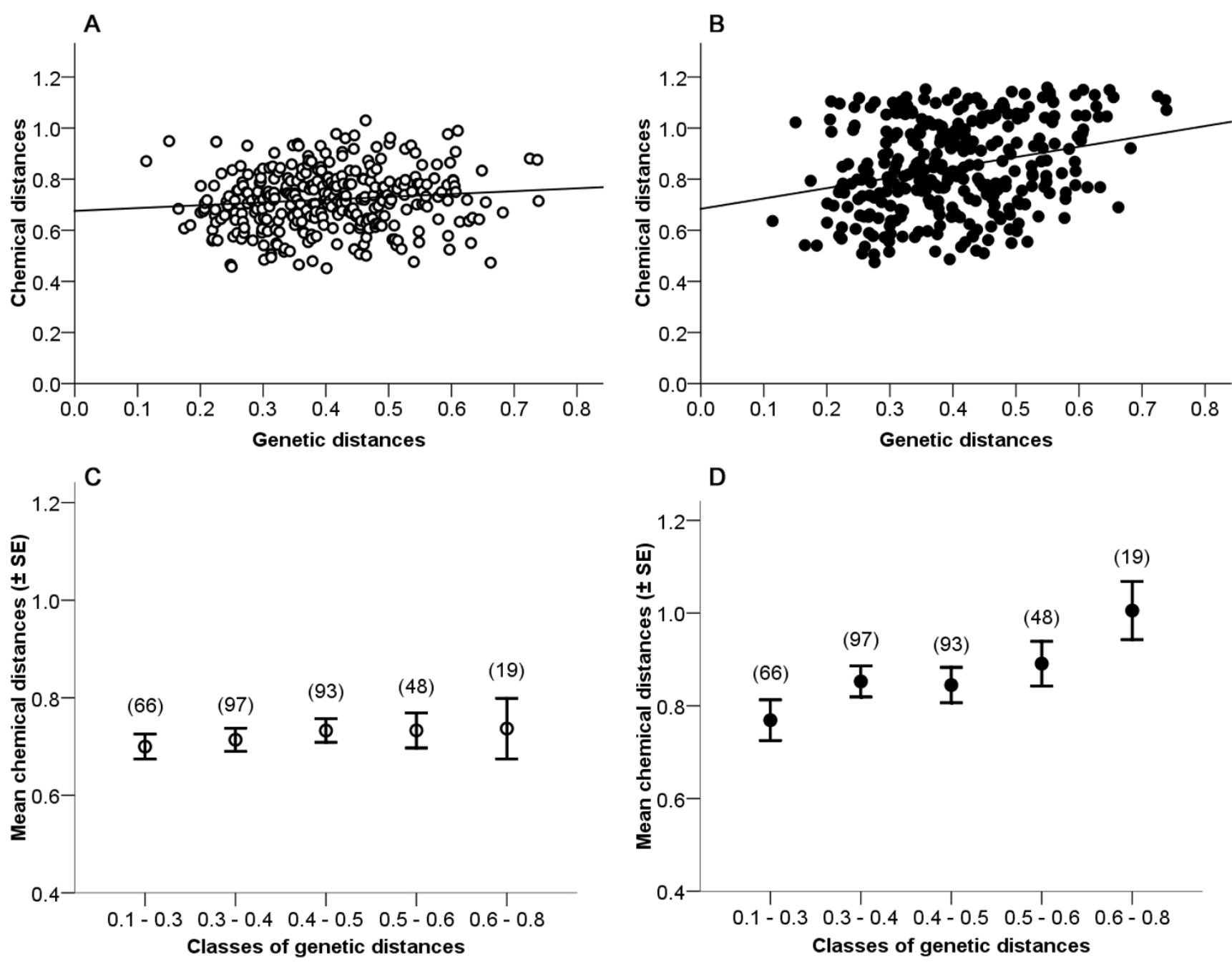

Figure 3

Odor-gene covariance in male-female dyads. Relationships between genetic distances $\left(D_{\text {ID }}\right)$ and chemical distances (relative Euclidean, from 170 compounds) in 323 male-female dyads during the nonbreeding (open circles, $A$ and $C$ ) and breeding (filled circles, B and D) seasons. The permutation tests on resampling events were performed on the data illustrated in A and $B$. The permutation tests based on class means were performed on the data illustrated in $C$ and $D$, which represent mean chemical distances per class of genetic distances, as defined in [27]. The maternal half-siblings (Figures I A-B) and the motherson (Figures I C-D) pairs belong to the first category of genetic distances $\left(D_{I D}=0.1\right.$ to 0.3$)$, whereas the unrelated pair (Figures I E-F) belong to the fourth category of genetic distances $\left(D_{I D}=0.5\right.$ to 0.6$)$.

Indeed, in socially complex species characterized by slow life histories, males may face significant reproductive costs that increase the benefits derived from being choosy. Thus, female and male lemurs may share similar selection pressures to avoid inbreeding.

Odor-gene covariance also raises the possibility that odor cues could serve to prevent outbreeding, again with similar benefits to both sexes. Outbreeding depression, although less well documented than inbreeding depression, can also produce negative consequences on fitness $[45,46]$. In only a few studies have researchers tested if odorants offer reliable cues that could serve to identify an optimally dissimilar mate and thereby help individuals avoid the fitness consequences of either inbreeding or outbreeding. In humans, individuals tend to pair with mates that are not too dissimilar at functional loci [47], but the sensory mechanism that may drive the avoidance of dissimilar mates remains unclear. In more extreme cases, odor-gene covariance could facilitate species or subspecies recognition. In callitrichid primates, for instance, the scent gland secretions from two subspecies (Saguinus fuscollis fuscollis and $S . f$. illigeri) contained distinctive chemical markers [48] and elicited discriminative 
responses by members of either subspecies [48,49]. Thus, it may be possible that odor-gene covariance mediates outbreeding avoidance within and between species [20]. Given that Lemur catta's nearest sister taxon belongs to a different genus (Hapalemur) [50], the threat of hybridization would seem less likely than the threat of inbreeding. Future studies could address the issue of outbreeding by comparing the scent gland semiochemistry of individuals derived from several populations or subspecies and measuring the behavioral responses the various mixtures of semiochemicals may elicit [20].

Although fascinating, it is unclear why the signal of genetic relatedness appears to be largely seasonally dependent. Consistent with the scent secretions of other mammals [51,52], including other primates [48,53,54], the labial and scrotal secretions of ring-tailed lemurs are extremely complex [35] and encode multiple messages [34]. Our permutation analyses suggest that the message of genetic relatedness between males and females may exist during the nonbreeding season also, but as a weaker signal. Perhaps, during the extended nonbreeding season, the message of genetic relatedness may become masked by the expression of compounds encoding other messages. Nonetheless, it could facilitate nepotism year round: Behavioral bioassays show that certain discriminatory responses of lemurs to the scent of conspecifics are limited to the breeding season and may be related to the selection of an appropriate mate, whereas others occur year round and may be related to nepotism (Charpentier MJE, Crawford JC, Boulet M, Drea CM: Lemurs Detect the Genetic Relatedness and Quality of Conspecifics via Olfactory Cues, submitted). Although we have not yet identified any specific semiochemicals responsible for broadcasting genetic relatedness, we have identified seasonal variation in semiochemical expression [27].

Also unclear is the manner by which olfactory signals come to represent an individual's genome. One possible mediating mechanism implicates genetic polymorphism in the enzymes involved in the biosynthesis of semiochemicals. For instance, semiochemical diversity could result from the action of desaturases $[55,56]$ or elongases [57] that modify hydrocarbon-based semiochemicals. While deciphering the biosynthetic pathways of insect pheromones [58], researchers have linked an individual's olfactory profile to the activation of various enzymes $[56,58]$ and have shown that semiochemicals, such as long-chained hydrocarbons, play a role in kin recognition and inbreeding avoidance [57-60]. As most of the semiochemicals found in lemur genital secretions are not present in their monkey chow (Sacha C, Dubay G, Boulet $\mathrm{M}$, and Drea CM; unpublished data), they appear to be endogenously produced and may be derived from common biosynthetic pathways (e.g., squalene is a precursor of cholesterol). Notably, the secretions of lemurs [35] share the diverse hydrocarbon-based semiochemicals found in other mammals [52]. Therefore, the enzymes involved in the synthesis of polymorphic semiochemicals could reflect genome-wide variation and be involved in mammalian chemical communication of genetic relatedness.

Alternatively, or in addition to biosynthetic pathways, an individual's semiochemical profile could be linked to the availability of polymorphic binding proteins that modify the bouquet of semiochemicals emitted by scent glands [61]. Lipocalins represent a large class of extracellular proteins that have the property of binding diverse hydrophobic molecules, such as fatty acids and fatty alcohols [62]. The lipocalin family includes MUPs, a group of binding proteins functioning as semiochemical transporters [63] and notably linked to inbreeding avoidance in mice [23]. These binding properties render lipocalins suitable candidate molecules for kin recognition. Interestingly, two MUP-related genes have been recently detected in the genome of the grey mouse lemur, Microcebus murinus [64].

Other candidates include the highly polymorphic MHC genes that are known to affect vertebrate mate choice and kin recognition through their influence on individual odor [21,22,65-68], although the pathway from MHC genes to individual odor profiles may not be completely resolved. In ring-tailed lemurs, specific MHC alleles may correlate with the abundance of some fatty acids present in scent secretions [69]. Data of this sort raise the possibility of an association between MHC genes and the pathways producing semiochemicals $[67,70]$. The relevant signal of genetic constitution could derive from the semiochemical profile alone or in conjunction with these various binding proteins, and could function in primates and other vertebrates to reveal genetic relatedness. The present findings have clear relevance to strepsirrhine primates and other mammals with functional vomeronasal organs (VNO), including platyrrhines (i.e., New World monkeys [71]). Given the functional overlap between the VNO and main olfactory epithelium $[63,72]$, however, these findings are also likely to extend to catarrhines (i.e., Old World monkeys and apes, including humans) that arguably lack a functional VNO $[73,74]$. Anthropoid primates produce a diversity of odorous substances (including scent-gland secretions, urine, and axillary sweat) $[12,52,54]$, the functional significance of which remains obscure and underappreciated. Nonetheless, human semiochemicals have been implicated in mother-infant recognition [75], recognition of familiar kin or non-kin [76], and possibly quality/compatibility-based mate choice $[68,77,78]$. We suggest that an olfactory mechanism could also function in various species to explain the scarcity of mating between unfamiliar kin (e.g. [18]), as well as 
paternal recognition and protection of offspring (e.g. [7982]).

\section{Conclusion}

We characterized the secretions expressed by the genital glands of male and female ring-tailed lemurs and showed that these chemical compounds encode genetic relatedness not only within the sexes, but even more strongly so between the sexes. We suspect the link between an individual's genome and its olfactory signals could be mediated in two ways: by biosynthetic pathways producing polymorphic molecules and/or by binding proteins modifying the bouquet of semiochemicals emitted by scent glands. We also found that the relationship between odor profiles and genetic relatedness emerges most strongly during the competitive breeding season, when such information would be crucial for preventing inbreeding and/or directing nepotistic or competitive behavior to appropriate recipients. Although behavioral studies will be necessary to verify the animals' sensitivity to chemically encoded information, we suggest that the seasonal convergence of a mutual olfactory signal between two sex-specific scent glands is likely to reflect strong selective pressure on mate choice. Signal convergence within the sexes may arise as a by-product of between-sex convergence, but could function independently to prevent competition or facilitate altruism between unfamiliar relatives. Our novel analytical approach for identifying odor-gene covariance holds significant promise for deciphering mechanisms of semiochemical signaling in vertebrates and calls specific attention to the important, though often neglected, role of olfactory communication in primates.

\section{Methods \\ Subjects and Housing}

Our female subjects were 17 reproductively intact adults (2-23 years old). Females and males were housed at the Duke Lemur Center (DLC) in Durham, North Carolina. Housing conditions have been described elsewhere $[27,35]$ and were in accordance with regulations of the United States Department of Agriculture and with the National Institutes of Health Guide for the Care and Use of Laboratory Animals. All research protocols were approved by the Institutional Animal Care and Use Committee of Duke University (protocol \#A245-03-07).

\section{Collection of odorants and chemical analyses}

Information about our collection procedure, odorant extraction, and gas-chromatography mass-spectrometry (GCMS) protocols has been provided elsewhere [27,35]. We collected scent samples over a period of years, spanning November 2003 to November 2007. This sampling period allowed us to maximize our subject pool, which otherwise would have been limited by pregnancy, contra- ception, immaturity, or death. The maximum time between collection and analysis was three years. We have previously verified sample preservation over freezer storage time [35], as have other researchers [83].

We analyzed chromatograms using the software Solution Workstation (Shimatzu Scientific Instruments). We retained semiochemicals that had consistent retention times and accounted for $\geq 0.05 \%$ of the area of the total chromatogram. To align the peaks between chromatograms, we standardized semiochemical retention times (rt) against the retention times of two standards: hexachlorobenzene $(\mathrm{rt}=12.6 \mathrm{~min})$ and squalene $(\mathrm{rt}=28.5$ min), a natural constituent of lemur genital secretions [35]. Semiochemicals were identified by comparing mass spectra against the NIST library, retention time of known compounds, and prior tentative identifications [35].

We compared the semiochemical diversity of secretions between seasons by generating the following indices: richness, Shannon, and Simpson [27]. These indices capture different aspects of the diversity present in semiochemical profiles: Whereas the richness index refers to the total number of semiochemicals per chromatogram, the Shannon and Simpson indices weight semiochemicals according to their abundance [36]. As the mathematical equations of the Shannon and Simpson indices are different, they generate distinct biases: the Shannon index is most strongly influenced by the compounds that are of intermediate abundance, whereas the Simpson index is most sensitive to the compounds that show the greatest abundance. All indices were computed in the software PCORD 5.20 [36].

For the analyses of odor-gene covariance in FF dyads, we retained 338 semiochemicals (retention time between 8.02 to $42.56 \mathrm{~min}$ ), which we expressed as peak area relative to the total area of the chromatogram. For similar analyses in mixed-sex dyads (MF), we first compared the 338 semiochemicals detected in labial samples to the 203 semiochemicals previously detected in scrotal secretions [27] to identify those semiochemicals shared by both sexes (i.e., those present in at least one male and one female). We then used only those 170 shared compounds in our mixed-sex analyses. As a proxy for chemical distance $\left(D_{C}\right)$, per season, we estimated the relative Euclidean distances between the semiochemical profiles of all possible dyads $(\mathrm{n}=171 \mathrm{MM}$ dyads; $\mathrm{n}=136$ FF dyads; $\mathrm{n}=$ 323 MF dyads) using the software PC-ORD 5.20 [36] and following previously published protocols.

\section{Genetic analyses}

We genotyped 81 DLC colony members at 11-14 microsatellite loci. These numbers differ slightly from those (i.e., $\mathrm{n}=73$ individuals at 9-14 loci) previously reported [27], 
reflecting the additional genotyping of some individuals at certain loci. We used the Identity index, $\mathrm{R}_{\mathrm{ID}}$, as an estimate of genetic relatedness [84] and transformed this index to obtain genetic distances, $\mathrm{D}_{\mathrm{ID}}$, using the following equation: $D_{I D}=1-R_{I D}$. We obtained similar results using the Queller and Goodnight index [85]. From all possible pairwise combinations, we retrieved those pairs involving subjects for which we had semiochemical data (partial Mantel test with 17 females: $\mathrm{n}=136 \mathrm{FF}$ dyads; partial Mantel test with 17 females and 19 males: $\mathrm{n}=630 \mathrm{MM}+$ $\mathrm{FF}+\mathrm{MF}$ dyads; permutation tests, $\mathrm{n}=323 \mathrm{MF}$ dyads).

\section{Statistical analyses}

We compared chemical diversity between male and female secretions by computing t-tests or t-tests for unequal variances (which adjusts the degrees of freedom). To test for seasonal differences in chemical diversity in female secretions, we used a paired t-test (SPSS 15.0 for Windows, SPSS Inc.). We tested for linear relationships between $D_{C}$ and $D_{I D}$ by computing partial Mantel tests (Fstat version 2.9.3.2; with 2000 randomizations and backward selection of variables, [86]). As in our previous study [27], we controlled for various potentially confounding factors, including the subject's age, their housing conditions, and the month of sample collection (see Additional file 1). For the partial Mantel test on MM + FF + MF dyads, we included sex as a supplementary co-variable (see Additional file 2). The matrices included $171 \mathrm{MM}$, 136 FF dyads, and 323 MF dyads.

As we were particularly interested in testing if genital scent secretions may encode information that could be used in the context of inbreeding avoidance, we again correlated chemical distances with genetic distances, focusing specifically on MF dyads. We used two types of permutation tests to address this question. For the first type of permutation test [37], we calculated the empirical correlation coefficients (see Additional file 3) between chemical and genetic distances of MF dyads and compared them against a distribution of correlation coefficients generated by 1000 permutation events (Resampling Stats for Excel, version 4.0). For the second type of permutation test, we categorized $\mathrm{D}_{\mathrm{ID}}$ values into 5 classes of genetic distances $(0.1$ to $0.3 ; 0.3$ to $0.4 ; 0.4$ to $0.5 ; 0.5$ to $0.6 ; 0.6$ to 0.8 ). These genetic classes follow those defined for the MM dyads by roughly equilibrating sample sizes across categories [27]. We then compared the mean chemical distances between these classes using randomization tests (PERM software, [38]). Each randomization test included 10 iterations of 1000 permutation events and $P$ values were averaged across all iterations. We applied sequential Bonferroni corrections to each pairwise comparison [87].

\section{Authors' contributions}

MB participated in the design of the study, carried out chemical analyses, performed statistical tests, and wrote the first draft of the manuscript. MJEC participated in the design of the study, carried out genetic work, performed statistical analyses and participated in drafting the manuscript. CMD conceived the research program in primate olfactory communication, participated in the design of the study and critically revised draft versions of the manuscript. All authors approved the final version of the manuscript.

\section{Additional material}

\section{Additional file 1}

Socio-demographic and environmental factors (female-female dyads only). Supplementary information and Table 1. Partial Mantel tests showing the seasonal relationships between semiochemical distances (relative Euclidean distances derived from 338 compounds) of female labial secretions versus genetic distances $\left(D_{I D}\right)$ and versus three socio-demographic or environmental factors taken as co-variables $(n=136 \mathrm{FF}$ dyads).

Click here for file

[http://www.biomedcentral.com/content/supplementary/14712148-9-281-S1.DOC]

\section{Additional file 2}

Socio-demographic or environmental factors (all possible dyads). Supplementary information and Table 2. Partial Mantel tests showing the seasonal relationships between semiochemical distances (relative Euclidean distances derived from 170 compounds) of lemur genital secretions versus genetic distances $\left(D_{I D}\right)$ and versus four socio-demographic or environmental factors taken as co-variables $(n=630 \mathrm{MM}+F F+M F$ dyads). Click here for file

[http://www.biomedcentral.com/content/supplementary/14712148-9-281-S2.DOC]

\section{Additional file 3}

Permutation tests based on 1000 resampling events, for $630 \mathrm{MM}+\mathrm{FF}$ + MF dyads and 323 MF dyads. Supplementary Table 3. Permutation tests showing the seasonal relationships between semiochemical distances of genital secretions versus genetic distances $\left(D_{I D}\right)$ for $M M+F F+M F$ dyads $(n=630)$ and for MF dyads only $(n=323)$.

Click here for file

[http://www.biomedcentral.com/content/supplementary/14712148-9-281-S3.DOC]

\section{Acknowledgements}

We thank D. Brewer, B. Schopler, J. Taylor, C. Williams, and S. Zehr for assistance with animal sampling at the Duke Lemur Center. We are particularly grateful to $G$. Dubay for his assistance with chemical analyses and for providing access to the Duke Chemistry Instrumentation Facility. Funding was provided by National Science Foundation research grants BCS0409367 and IOS-07 19003 (to CMD), Natural Sciences and Engineering Research Council Fellowship (to MB), and an Outgoing Marie Curie Fellowship (to MJEC). This is DLC publication \# II 54.

\section{References}

I. Hepper PG: Kin Recognition Cambridge: Cambridge University Press; |99|.

2. Pusey A: Inbreeding avoidance in primates. In Inbreeding, Incest, and the Incest Taboo Edited by: Wolf AP, Durham DH. Stanford: Stanford University Press; 2004:6I-75. 
3. Holmes WE, Mateo JM: Kin Recognition in Rodents: Issues and Evidence. In Rodent Societies: An Ecological \& Evolutionary Perspective Edited by: Wolff JO, Sherman PW. Chicago: The University of Chicago Press; 2007:216-228.

4. Sackett GP, Frederickson WT: Social preferences by pigtailed macaques: familiarity versus degree and type of kinship. Animal Behaviour 1987, 35:603-606.

5. Wu HMH, Holmes WG, Medina SR, Sackett GP: Kin preference in Macaca nemestrina. Nature 1980, 285:225-227.

6. Alberts SC: Paternal kin discrimination in wild baboons. Proceedings of the Royal Society of London Series B-Biological Sciences 1999 266: $1501-1506$.

7. Widdig A: Paternal kin discrimination: the evidence and likely mechanisms. Biological Reviews 2007, 82:319-334.

8. Crnokrak P, Roff DA: Inbreeding depression in the wild. Heredity 1999, 83:260-270.

9. Keller LF, Waller DM: Inbreeding effects in wild populations. Trends in Ecology and Evolution 2002, I 7:230-24I.

10. Charpentier MJE, Widdig A, Alberts SC: Inbreeding depression in non-human primates: a historical review of methods used and empirical data. American Journal of Primatology 2007, 69:1370-I386.

II. Hebets EA, Papaj DR: Complex signal function: developing a framework of testable hypotheses. Behavioral Ecology and Sociobiology 2005, 57:197-214.

12. Wyatt TD: Pheromones and Animal Behaviour Cambridge: Cambridge University Press; 2003.

13. Müller-Schwarze D: Chemical Ecology of Vertebrates Cambridge: Cambridge University Press; 2006.

14. Widdig A, Nürnberg M, Krawczak M, Streich WJ, Bercovitch FB: Paternal relatedness and age proximity regulate social relationships among adult female rhesus macaques. Proceedings of the National Academy of Sciences of the United States of America 200I, 98:13769-13773.

15. Charpentier MJE, Peignot P, Hossaert-McKey M, Wickings JE: Kin discrimination in juvenile mandrills (Mandrillus sphinx). Animal Behaviour 2007, 73:37-45.

16. Winn BE, Vestal BM: Kin recognition and choice of males by wild female house mice (Mus musculus). Journal of Comparative Psychology 1986, II I:72-75.

17. Smith K, Alberts SC, Altmann J: Wild female baboons bias their social behaviour towards paternal half-sisters. Proceedings of the Royal Society of London Series B-Biological Sciences 2003, 270:503-510.

18. Muniz L, Perry S, Manson JH, Gilkenson H, Gros-Louis J, Vigilant L. Father-daughter avoidance in a wild primate population. Current Biology 2006, 16:156-157.

19. Archie EA, Hollister-Smith JA, Poole JH, Lee PC, Moss CJ, Maldonado JE, Fleischer RC, Alberts SC: Behavioural inbreeding avoidance in wild African elephants. Molecular Ecology 2007, 16:4|38-4| 48.

20. Todrank J, Heth G: Odor-genes covariance and genetic relatedness assessments: rethinking odor-based 'recognition' mechanisms in rodents. Advances in the Study of Behavior 2004 32:77-130 [http://books.google.com/ books?hl=en\&lr=\&idXJFTJ6xsYcC\&oi=fnd\&pg=PA77\&dq=Todrank + Heth+Advances\&o=qppHTN

FEUI\&sig=TbjTCWuZul54qa74B6F9QaJP65o\#v=onepage\&q=Todran k\%20Heth\%20Advances\&f=false]. San Diego: Academic Press

21. Willse A, Belcher AM, Preti G, Wahl JH, Thresher M, Yang P, Yamazaki K, Beauchamp GK: Identification of Major Histocompatibility Complex-regulated body odorants by statistical analysis of a comparative Gas Chromatography/Mass Spectrometry experiment. Analytical Chemistry 2005, 77:2348-2361.

22. Willse A, Kwak J, Yamazaki K, Preti G, Wahl JH, Beauchamp GK Individual odortypes: interaction of MHC and background genes. Immunogenetics 2006, 58:967-982.

23. Sherborne AL, Thom MD, Paterson S, Jury F, Ollier WER, Stockley $P$, Beynon RJ, Hurst JL: The Genetic Basis of Inbreeding Avoidance in House Mice. Current Biology 2007, 17:206I-2066.

24. Cheetham SA, Thom MD, Jury F, Ollier WER, Beynon RJ, Hurst J The Genetic Basis of Individual-Recognition Signals in the Mouse. Current Biology 2007, 17:177I-1777.

25. Safi K, Kerth G: Secretions of the interaural gland contain information about individuality and colony membership in Bechstein's bat. Animal Behaviour 2003, 65:363-369.
26. Sun LX, Müller-Schwarze D: Anal gland secretion codes for relatedness in the beaver, Castor canadensis. Ethology 1998, 104:917-927.

27. Charpentier MJE, Boulet M, Drea CM: Smelling right: the scent of male lemurs advertises genetic quality and relatedness. Molecular Ecology 2008, 17:3225-3233.

28. Jolly A: Lemur behavior: A Madagascar field study Chicago: The University of Chicago Press; 1966.

29. Sussman RW: Social behavior and aggression among ringtailed lemurs. American Journal of Physical Anthropology 199I, 84:43-58.

30. Vick LG, Pereira ME: Episodic targeting aggression and the histories of lemur social-groups. Behavioral Ecology and Sociobiology 1989, 25:3-12.

31. Charpentier MJE, Williams CV, Drea CM: Inbreeding depression in ring-tailed lemurs (Lemur catta): genetic diversity predicts parasitism, immunocompetence, and survivorship. Conservation Genetics 2008, 9:1605-1615.

32. Shilling A: Olfactory communication in Prosimians. In The Study of Prosimian Behavior Edited by: Doyle GA, Martin RD. New York: Academic Press; 1979:46I-542.

33. Palagi E, Dapporto L: Beyond odor discrimination: demonstrating individual recognition by scent in Lemur catta. Chemical Senses 2006, 31:437-443.

34. Scordato ES, Drea CM: Scents and sensibility: information content of olfactory signals in the ringtailed lemur, Lemur catta. Animal Behaviour 2007, 73:30I-314.

35. Scordato ES, Dubay G, Drea CM: Chemical composition of scent marks in the ringtailed lemur (Lemur catta): Glandular differences, seasonal variation, and individual signatures. Chemical Senses 2007, 32:493-504.

36. McCune B, Grace JB, Urban DL: Analysis of Ecological Communities Gleneden Beach: MjM Software Design; 2002.

37. Simon J: Resampling: the new statistics. 2nd edition. 1997 [http:/ /www.resample.com/content/text/index.shtml].

38. Duchesne P, Étienne P, Bernatchez L: PERM: A computer program to detect structuring factors in meaningful social units. Molecular Ecology Notes 2006, 6:965-976.

39. Drea CM, Weil A: External genital morphology of the ringtailed lemur (Lemur catta): Females are naturally 'masculinized'. Journal of Morphology 2008, 269:45I-463.

40. Kraaijeveld K, Kraaijeveld-Smit FJL, Kromdeur J: The evolution of mutual ornamentation. Animal Behaviour 2007, 74:647-677.

4I. Mason RT, Crews D: Female mimicry in garter snakes. Nature 1985, 316:59-60.

42. Mason RT: Chemical ecology of the red-sided garter snake, Thamnophis sirtalis parietalis. Brain, Behavior, and Evolution 1993, 41:26I-268

43. LeMaster MP, Stefani A, Shine R, Mason RT: Cross-dressing in chemical cues: exploring 'she-maleness' in newly-emerged male garter snakes. In Chemical Signals in Vertebrates II Edited by: Hurst JL, Beynon RJ, Roberts CS, Wyatt TD. New York: Springer; 2008:223-230

44. Drea CM: Bateman revisited: The reproductive tactics of female primates. Integrative and Comparative Biology 2005, 45:915-923

45. Lynch M: The genetic interpretation of inbreeding depression and outbreeding depression. Evolution 1991, 45:622-629.

46. Edmands S: Between a rock and a hard place: evaluating the relative risks of inbreeding and outbreeding for conservation and management. Molecular Ecology 2007, 16:463-475.

47. Rushton JP: Genetic similarity, mate choice, and fecundity in humans. Ethology and Sociobiology 1988, 9:329-333.

48. Epple G, Golob NF, Cebul M-S, Smith IAB: Communication by scent in some Callitrichidae (Primates) - An interdisciplinary approach. Chemical Senses 198I, 6:377-389.

49. Epple G, Alveario MC, Belcher AM, Smith IAB: Species and subspecies specificity in urine and scent marks of saddle-back tamarins (Saguinus fuscollis). International Journal of Primatology 1987, 8:663-680.

50. Horvath JE, Weisrock DW, Embry SL, Fiorentino I, Balhoff JP, Kappeler P, Wray GA, Willard HF, Yoder AD: Development and application of a phylogenomic toolkit: Resolving the evolutionary history of Madagascar's lemurs. Genome Research 2008, 18:489-499. 
5I. Johnston RE: Chemical communication in rodents: from pheromones to individual recognition. Journal of Mammalogy 2003, 84: $|14|-|| 62$

52. Burger BV: Mammalian Semiochemistry. Topics in Current Chemistry 2005, 240:23I-278.

53. Epple G, Belcher AM, Kuderling I, Zeller U, Scolnick L, Greenfield KL, Smith $A B I$ : Making sense out of scents: species differences in scent glands, scent-marking behaviour, and scent-mark composition in the Callitrichidae. In Marmosets and Tamarins: Systematics, Behaviour, and Ecology Edited by: Rylands AB. Oxford: Oxford University Press; 1993:123-151.

54. Penn DJ, Oberzaucher E, Grammer K, Fischer G, Soini HA, Wiesler D, Novotny MV, Dixon SJ, Xu Y, Brereton RG: Individual and gender fingerprints in human body odour. Journal of the Royal Society Interface 2007, 4:331-340.

55. Takahashi A, Tsaur S-C, Coyne JA, Wu C-I: The nucleotide changes governing cuticular hydrocarbon variation and their evolution in Drosophila melanogaster. Proceedings of the National Academy of Sciences of the United States of America 200I, 98:3920-3925

56. Roelofs WL, Rooney AP: Molecular genetics and evolution of pheromone biosynthesis in Lepideptora. Proceedings of the National Academy of Sciences of the United States of America 2003, 100:9179-9184.

57. Chertemps T, Duportets L, Labeur C, Ueda R, Takahashi K, Saigo K, Wicker-Thomas C: A female-biased expressed elongase involved in long-chain hydrocarbon biosynthesis and courtship behavior in Drosophila melanogaster. Proceedings of the National Academy of Sciences of the United States of America 2007, 104:4273-4278.

58. Howard WH, Blomquist G]: Ecological, behavioral, and biochemical aspects of insect hydrocarbons. Annual Review of Entomology 2005, 50:37|-393.

59. Lihoreau M, Zimmer C, Rivault C: Kin recognition and incest avoidance in a group-living insect. Behavioral Ecology 2007, 18:880-887.

60. Lihoreau M, Rivault C: Kin recognition via cuticular hydrocarbons shapes cockroach social life. Behavioral Ecology 2009, 20:46-53.

61. Boehm T, Zufall F: MHC peptides and the sensory evaluation of genotype. Trends in Neurosciences 2006, 29:100-107.

62. Flower DR: The lipocalin protein family: structure and function. Biochemical Journal 1996, 318:1-14.

63. Brennan A, Keverne $E$ : Something in the air? New insights into mammalian pheromones. Current Biology 2004, I 4:R8I-R89.

64. Logan DW, Marton TF, Stowers L: Species specificity in major urinary proteins by parallel evolution. PLOS ONE 2008, 3:e3280.

65. Singer AG, Beauchamp GK, Yamazaki K: Volatile signals of the major histocompatibility complex in male mouse urine. Proceedings of the National Academy of Sciences of the United States of America 1997, 94:2210-2214.

66. Penn DJ: The scent of genetic compatibility: sexual selection and the major histocompatibility complex. Ethology 2002, I08:|-2|.

67. Novotny MV, Soini H, Koyama S, Wiesler D, Bruce K, Penn D: Chemical Identification of MHC-influenced Volatile Compounds in Mouse Urine. I: Quantitative Proportions of Major Chemosignals. Journal of Chemical Ecology 2007, 33:417-434.

68. Chaix R, Cao C, Donnelly P: Is mate choice in humans MHCdependant? PLOS Genetics 2008, 4:9.

69. Knapp LA, Robson J, Waterhouse JS: Olfactory signals and the MHC: a review and a case study in Lemur catta. American Journal of Primatology 2006, 68:568-584.

70. Yamazaki K, Beauchamp GK: Genetic basis for MHC-dependant mate choice. Advances in Genetics 2007, 59:129-I45.

71. Evans C: Vomeronasal Chemoreception in Vertebrates: a Study of the Second Nose London: Imperial College Press; 2003.

72. Sheperd GM: Smells, brains, and hormones. Nature 2006, 439:|49-|5|.

73. Halpern M, Martínez-Marcos A: Structure and function of the vomeronasal system: an update. Progress in Neurobiology 2003, 70:245-3/8.

74. Wysocki CJ, Preti G: Facts, fallacies, fears, and frustrations with human pheromones. Anatomical Record A 2004, 2 I 8A: I 201-12 II.

75. Schaal B, Doucet S, Soussignan R, Rietdorf M, Weibchen G, Francke $W$ : The human breast as a scent organ: exocrine structures, secretions, volatile components, and possible functions in breastfeeding interactions. In Chemical Signals in Vertebrates Edited by: Hurst JL, Beynon RJ, Roberts CS, Wyatt TD. New York: Springer; 2008:325-335

76. Lundström JN, Boyle JA, Zatorre RJ, Jones-Gotman M: The neuronal substrates of human olfactory based kin recognition. Human Brain Mapping 2009, 30:257| -2580.

77. Wedekind C, Seebeck T, Bettens F, Paepke AJ: MHC-dependent mate preferences in humans. Proceedings of the Royal Society B-Biological Sciences 1995, 260:245-249.

78. Ober C, Weitkamp LR, Cox N, Dytch H, Kostyu D, Elias S: HLA and mate preferences in humans. American Journal of Human Genetics 1997, 6 I:497-504.

79. Borries C, Launhardt K, Epplen C, Epplen JT, Winkler P: Males as infant protectors in Hanuman langurs (Presbytis entellus) living in multimale groups - defence pattern, paternity and sexual behaviour. Behavioral Ecology and Sociobiology 1999, 46:350-356.

80. Soltis J, Thomsen R, Matsubayashi K, Takenaka O: Infanticide by resident males and female counterstrategies in wild Japanese macaques (Macacca fuscata). Behavioral Ecology and Sociobiology 2000, 48: 195-202.

81. Buchan JC, Alberts SC, Silk JB, Altmann J: True paternal care in a multi-male primate society. Nature 2003, 425: I79-181.

82. Lehmann J, Fickenscher G, Boesch C: Kin biased investment in wild chimpanzees. Behaviour 2006, I43:93I-955.

83. Lenochova P, Roberts SC, Havlicek J: Methods of human odor sampling: the effects of freezing. Chemical Senses 2008, 34:127-138.

84. Mathieu E, Autem M, Roux M, Bonhomme F: Épreuves de la validation dans I'analyse de structures génétiques multivariées: comment tester l'équilibre panmictique? Revue de Statistiques Appliquées 1990, 38:47-66.

85. Queller D, Goodnight K: Estimating relatedness using genetic markers. Evolution 1989, I I:201-206 [http://www.jstor.org/pss/ 2409206].

86. Goudet J: FSTAT, a program to estimate and test gene diversities and fixation indices (version 2.9.3, 200I). 200I [http:/l www2.unil.ch/popgen/softwares/fstat.htm].

87. Rice WR: Analyzing tables of statistical of statistical tests. Evolution 1989, 43:223-225.

\section{Publish with Biomed Central and every scientist can read your work free of charge}

"BioMed Central will be the most significant development for disseminating the results of biomedical research in our lifetime. "

Sir Paul Nurse, Cancer Research UK

Your research papers will be:

- available free of charge to the entire biomedical community

- peer reviewed and published immediately upon acceptance

- cited in PubMed and archived on PubMed Central

- yours - you keep the copyright
BioMedcentral 